\title{
Traduire
}

Ine autre perspective sur I t raduction

Revue française de la traduction

245 | 2021

Regards sur l'interprétation

\section{La Voix d'Aïda, film écrit et réalisé par Jasmila} Žbanic

\section{Émilie Syssau}

\section{(2) OpenEdition}

1 Journals

\section{Édition électronique}

URL : https://journals.openedition.org/traduire/2499

DOI : 10.4000/traduire.2499

ISSN : 2272-9992

Éditeur

Société française des traducteurs

\section{Édition imprimée}

Date de publication : 5 décembre 2021

Pagination : 107-109

ISSN : 0395-773X

\section{Référence électronique}

Émilie Syssau, "La Voix d'Aïda, film écrit et réalisé par Jasmila Žbanic », Traduire [En ligne], 245 | 2021, mis en ligne le 05 décembre 2021, consulté le 23 décembre 2021. URL : http://

journals.openedition.org/traduire/2499; DOI : https://doi.org/10.4000/traduire.2499 


\section{Vu pour vous}

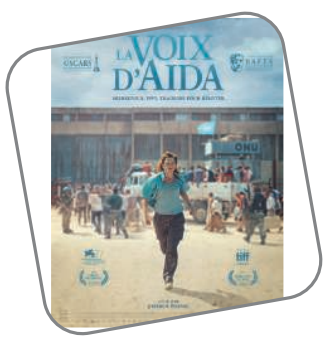

La Voix d'Aïda

Film écrit et réalisé par Jasmila Žbanic

\section{Émilie Syssau}

Avec La Voix d'Aïa, la réalisatrice bosniaque Jasmila Žbanic, diplômée de l'Académie des arts dramatiques, du théâtre et du cinéma de Sarajevo, signe son cinquième long métrage de fiction, après Sarajevo, mon amour (Ours d'or de la Berlinale en 2006), Le Choix de Luna (présenté en 2010 en compétition officielle au festival de Berlin), Les Femmes de $\checkmark$ isegrad et Love Island (diffusé sur Arte). Elle a également réalisé plusieurs documentaires.

Le film est librement inspiré du récit autobiographique Pod zastavom UN-a [Sous le drapeau de l'ONU; inédit en français, traduit en anglais sous le titre Under the UN Flag] du Bosniaque Hasan Nuhanović. Traducteur-interprète, celuici a travaillé avec le contingent néerlandais Dutchbat III de la Force de protection des Nations unies (FORPRONU) chargé de protéger la «zone de sécurité» des Nations unies à Srebrenica à la fin de la guerre de Bosnie (1992-1995). Son père fut l'un des trois représentants des 30000 personnes réfugiées dans et aux abords de la base de Potoćari à participer en juillet 1995 à de prétendues négociations avec le général Mladić, aux côtés d'officiers supérieurs néerlandais; à l'issue de ces discussions, des bus ont été acheminés vers la base pour emmener femmes et enfants, tandis que les hommes étaient sommés de monter dans des camions qui les conduiraient en réalité sur le lieu de leur exécution. Les interventions répétées de Hasan Nuhanović pour protéger 
sa famille ont été vaines: sa mère, son père et son frère ont été remis par les soldats de l'ONU à l'armée serbe et assassinés. Ils comptent au nombre des plus de 8000 habitants de Srebrenica massacrés le 11 juillet 1995. Cette date et ces faits sont aujourd'hui traumatiques en Bosnie.

La Voix d'Aïda transpose et inverse les liens de parenté: le film met ainsi en scène Aïda, une professeure d'anglais embauchée comme interprète au camp des Casques bleus installé près de Srebrenica. Préposée à la traduction des consignes, faussement rassurantes, adressées aux habitants qui fuient la ville à l'approche des troupes serbes, elle acquiert rapidement la certitude que le pire ne peut être évité. Son intuition est étayée par les rumeurs qui circulent et par le constat que les Casques bleus, abandonnés, depuis New York, par l'ONU, sont livrés à eux-mêmes. Faute de pouvoir agir pour tous, Aïda tente alors de sauver au moins son mari et ses deux fils adultes, bloqués à l'extérieur du camp. Pour les y faire entrer, elle propose que son époux, professeur d'histoire et proviseur du lycée de Srebrenica, participe aux négociations pour lesquelles le général serbe Mladić a requis la présence de trois représentants des réfugiés. Sans laisser le temps aux forces néerlandaises de préparer un plan d'évacuation et d'escorte des réfugiés, comme convenu, le général serbe affrète (et impose) les véhicules qui les conduiront à la mort...

Le film montre une femme piégée entre deux mondes. Bosniaque, elle voit ses proches partager la situation des réfugiés de Srebrenica, alors qu'elle-même se pense protégée du fait de son travail pour l'ONU: ayant foi en l'organisation internationale, elle croit pouvoir tirer certains privilèges du fait de son implication, notamment la sécurité de sa famille sur la base. Les événements lui montreront cependant qu'elle a trop présumé du bénéfice de sa situation, pour le moins ambiguë. De façon cruelle, ce long métrage interroge la neutralité de l'interprète: comment remplir sa mission quand on voudrait, à rebours du message à délivrer, mettre en garde ses interlocuteurs? Peut-on, par respect de la déontologie professionnelle qui veut que l'on interprète strictement les propos confiés, contribuer à livrer les siens à leurs bourreaux? 
La Voix d'Aïda souligne aussi la précarité de la situation des interprètes et de leurs familles; on entrevoit, en filigrane, le danger qu'ils courent à travailler au côté d'un camp plutôt que d'un autre dans un contexte de guerre. Force est de penser, plus près de nous, au déplorable abandon de nombreux interprètes afghans par les Occidentaux ${ }^{1}$...

La Voix d'Aïda, un film écrit et réalisé par Jasmila Žbanic - 2020 Couleur - 104 min - Bosnie, Allemagne, France. 